\title{
Response of a zooplankton community to the addition of unsaturated fatty acids: an enclosure study
}

\author{
MAARTEN BOERSMA and CLAUS-PETER STELZER \\ Max-Planck-Institut für Limnologie, Postfach 165, D-24302 Plön, Germany
}

\section{SUMMARY}

1. The effect of the addition of emulsions with different fatty acid composition to a semi-natural zooplankton community was studied in enclosures.

2. The reactions of different taxa in the zooplankton community to the addition of the emulsions were different. The copepods showed almost no reaction, nor did the selective cladocerans (Bosmina) or rotifers (Synchaeta or Polyarthra). The non-selective filterfeeding cladocerans Daphnia and Ceriodaphnia, and the rotifer Keratella, showed responses to the addition of the emulsions.

3. Keratella showed the highest density in the enclosures with high amounts of highly unsaturated fatty acids added, whereas both Daphnia and Ceriodaphnia reached the highest numbers in the enclosures where we added emulsions of saturated fatty acids only.

4. Our results suggest that different taxa may be limited by different factors, even though they use similar food sources. Hence, we conclude that it is very difficult to generalize on the limiting factors in aquatic systems.

Keywords: Daphnia, fatty acid, food quality, HUFA, rotifers

\section{Introduction}

The effect of food quality on zooplankton growth and reproduction has been an active area in aquatic research, as demonstrated by the high output on this subject matter in the last few years (e.g. reviews by Gulati \& DeMott, 1997; Sterner \& Schulz, 1998). Two, more or less distinct, approaches can be distinguished in the literature. The main focus of the first approach is on individual responses of zooplankters to experimental manipulation of food in the laboratory (e.g. Sterner, 1993; Müller-Navarra, 1995b; DeMott, Gulati \& Siewertsen, 1998). The second approach uses observational and correlation studies of specific zooplankton densities with the characteristics of their habitat (e.g. Elser \& Hassett, 1994; Sterner et al., 1997). Studies in the first group typically involve the culture of individual zooplankters under different food condi-

\footnotetext{
Correspondence: M. Boersma, Max-Planck-Institut für Limnologie, Postfach 165, D-24302 Plön, Germany.

E-mail: boersma@mpil-ploen.mpg.de
}

(c) 2000 Blackwell Science Ltd tions, such as different algal species (Lundstedt \& Brett, 1991; Boersma \& Vijverberg, 1995), algae grown under different limitations (Sterner, Hagemeier \& Smith, 1993; Müller-Navarra, 1995b), natural seston (Goulden et al., 1998) or food supplemented with different additions (Sundbom \& Vrede, 1997; Weers \& Gulati, 1997a). The second approach usually consists of the collection of data from a wide array of different habitats, measuring such features of the system as total phosphorus or C:P ratios of the seston. Subsequently, these data are analysed in an attempt to establish the relationship between the composition of the zooplankton community and the characteristics of the habitat (Hessen, 1992; Elser \& Hassett, 1994; Sterner et al., 1997). The advantage of the first approach is that we gain insight into the individual responses of different zooplankton species to food of different quality, but the extrapolation of these insights to field situations is difficult. The advantage of the second approach is that it allows the generation of testable hypotheses, but does not yield much insight in the mechanisms steering the observed patterns. 
All of the studies cited above have essentially concentrated on three aspects of nutritional quality of seston for zooplankters. First, the size and morphology of the algae in the seston is of importance. If the size of the food particles is too small (Brendelberger, 1991), or too large (Bern, 1994), or if the cells have protective structures such has thick cell walls (van Donk et al., 1997) or gelatinous sheaths (Porter, 1976), the quality of the algae as a food source is low, since the zooplankters cannot ingest or digest these resources. Second, the mineral composition of the algae/seston can influence its nutritional quality; in freshwater systems in particular, phosphorus has been found to be a major determining factor. If the phosphorus concentration of algae is low, nutritional quality of the food is low (Urabe, Clasen \& Sterner, 1997; DeMott et al., 1998). Third, biochemical features of the food, such as the fatty acid content, determine the quality of the food. Especially the highly unsaturated fatty acids (HUFA), such as eicosapentaenoic acid (EPA) and docosahexaenoic acid (DHA), are essential for many consumers, and several studies have indicated the importance of these fatty acids for herbivorous zooplankton (Müller-Navarra, 1995a,b; Brett \& Müller-Navarra, 1997; Sundbom \& Vrede, 1997; Weers \& Gulati, 1997b). However, with particular regard to the effect of biochemical limitations of the seston for zooplankters, experimental work under (semi-) natural conditions is lacking. Hence, in this study we set out to investigate the effect of the addition of different fatty acid emulsions on a seminatural community of zooplankton, and carried out an enclosure experiment. The approach is not new; the addition of emulsions of highly unsaturated fatty acids has been carried out in laboratory experiments (DeMott \& Müller-Navarra, 1997; Boersma, in press). Moreover, it is widely used in aquaculture (Coutteau \& Sorgeloos, 1997), where the addition of these emulsions has resulted in a substantial increase in growth of the target organisms. Especially non-selective filterfeeders, such as Artemia and Brachionus, take up the emulsions readily, and in turn are used as food for commercially valuable species. However, as stated above, this approach has not been used as yet under semi-natural conditions. The experiment we carried out is relatively short-term, and the different treatments are not expected to lead to new equilibrial situations within the experiment. However, the way densities of the zooplankters change should indicate whether the fatty acids under investigation did limit zooplankton growth.

Hence, we added emulsions with a different fatty acid composition. One, with mainly saturated and mono-unsaturated fatty acids, and two with different concentrations of highly unsaturated fatty acids. We hypothesized that if HUFAs are limiting zooplankton growth, we would find the highest zooplankton density in the enclosures with the highest concentration of HUFAs. Alternatively, if energy rather than HUFAs limits zooplankton growth, we expect no effect of the exact composition of the emulsion, but an effect of the addition of a readily available energy source, and hence a higher density in the emulsion enclosures than in the controls. Furthermore, we hypothesized that we would mainly observe a response for the non-selective filterfeeders, such as Daphnia and Keratella. We expected a smaller effect on the density of more selective feeders, such as copepods, because these organisms might not take up the emulsions readily.

\section{Methods}

An enclosure experiment was carried out in MayJune 1997 in Schöhsee, a lake near the Max Planck Institute in Plön, to investigate the effect of different fatty acids on the whole zooplankton community. The enclosures were $3.5 \mathrm{~m}$ in length, closed at the bottom and with a total volume of around $2 \mathrm{~m}^{3}$. They were filled with the natural community of plankton. We exposed the enclosures to four different treatments to investigate the effect of the addition of fatty acids to the natural seston. The treatments consisted of the addition of different emulsions of fatty acids supplied by INVE technologies, Belgium (Coutteau et al., 1996). These emulsions were standard emulsions made available through the International Council for the Exploration of the Sea (ICES) working group on mass rearing juvenile fish. They included: ICES 30/ 0.6/C (HIGH), ICES 10/0.6/C (MIDDLE) and ICES $0 /-/ C(L O W)$. The emulsions differ in their fatty acid composition. The LOW-emulsion consists mainly of saturated and mono-unsaturated fatty acids, the MIDDLE-emulsion contains 10\% highly unsaturated fatty acids, mainly EPA (eicosapentaenoic acid;

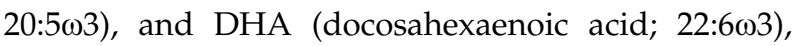
and $\mathrm{HIGH}$ contains $30 \%$ of these long-chained polyunsaturated fatty acids (Weers \& Gulati, 1997a; 
Boersma, in press). The fatty acids in the emulsions are not free fatty acids, but bound in triglycerides. All emulsions contain emulsifiers and anti-oxidants. Every day, fresh emulsions were prepared by adding $0.25 \mathrm{mg}$ wet weight of emulsion per L to the enclosures. In total, we had eight enclosures, all treatments were carried out in duplicate. After the addition of the emulsions, the enclosures were mixed. Probably, a part of the unsaturated fatty acids was oxidized to saturated forms through the course of the experiment. However, as we added new emulsions daily, the effect of this was probably not large.

Samples were taken every 2 days and, before sampling, the enclosures were thoroughly mixed with a Secchi disk. Total zooplankton biomass was established by filtering $1 \mathrm{~L}$ of water through a pre-weighed $30-\mu \mathrm{m}$ plankton gauze, drying this gauze, and subsequent weighing. For the rotifers, the samples were taken with a 2-L Ruttner sampler. The samples were preserved in a $4 \%$ formaldehyde solution, sedimented in $50 \mathrm{~mL}$ Utermöhl chambers and counted with an inverted microscope. Larger zooplankters were sampled with a vertical tow using a $120-\mu \mathrm{m}$ plankton net, preserved in $70 \%$ ethanol and counted. Chlorophyll $a$ in the enclosures was measured using an in situ fluorescence probe (Dr Hardt Mikro-Elektronik, Germany). A repeated measures ANOVA, with the treatments as the fixed factor and the different samples through time as the repeated measures, was used to investigate the effect of the different treatments on the density of the different taxa. On two occasions during the experiment (day 14 and day 28) we estimated the density of the most dominant algal groups and of bacteria present in the enclosures. This was carried out using the Ruttner sampler and subsequent preservation of the algae in Lugol's solution and of the bacteria in $4 \%$ formalin. Phytoplankton samples were sedimented in Utermöhl chambers and counted at $500 \times$ or $125 \times$ magnification. The algae were identified to genus. Bacterial density was established by filtering $1 \mathrm{ml}$ through a $0.2 \mu \mathrm{m}$ nuclepore filter and counting under epifluorescence with DAPI as a fluorochrome (Porter \& Feig, 1980).

During the experiment, which took place around the clear-water phase, we observed that initial growth in all enclosures was very low. Hence, we concluded that the total amount of resources was so low that the zooplankters were close to starvation. Therefore, in order to boost growth, we added $0.3 \mathrm{mg} \mathrm{C} \mathrm{L}^{-1}$ of laboratory cultured Scenedesmus obliquus Turpin (Kuetzing) on days 18 and 20 of the experiment.

\section{Results}

There was no detectable effect of the different treatments on the total biomass of the seston $>30 \mu \mathrm{m}$ (Fig. 1). Although we observed differences in biomass among treatments, the rank order of these differences did not change systematically over time, hence reflecting initial conditions, and possible sampling variation, rather than real treatment effects. From the very low chlorophyll $a$ levels present in the enclosures, we concluded that the food supply was so low that the addition of the fatty acids was unlikely to influence growth, as animals cannot grow on fatty acids alone. Hence, the first conclusion of our study is that, in our study period, the addition of different fatty acid emulsions alone did not play a role, and hence, the zooplankters in the enclosures were not limited by essential fatty acids. The addition of the algae led to a significant increase in the biomass $>30 \mu \mathrm{m}$, but still did not reveal clear treatment effects (Fig. 1). The absence of an effect on total biomass in the enclosure could be due to a number of reasons. First, none of the zooplankters present in the enclosures responded to the treatments. Second, only a minor fraction of the zooplankters responded and, third, zooplankters responded in different ways, leav-

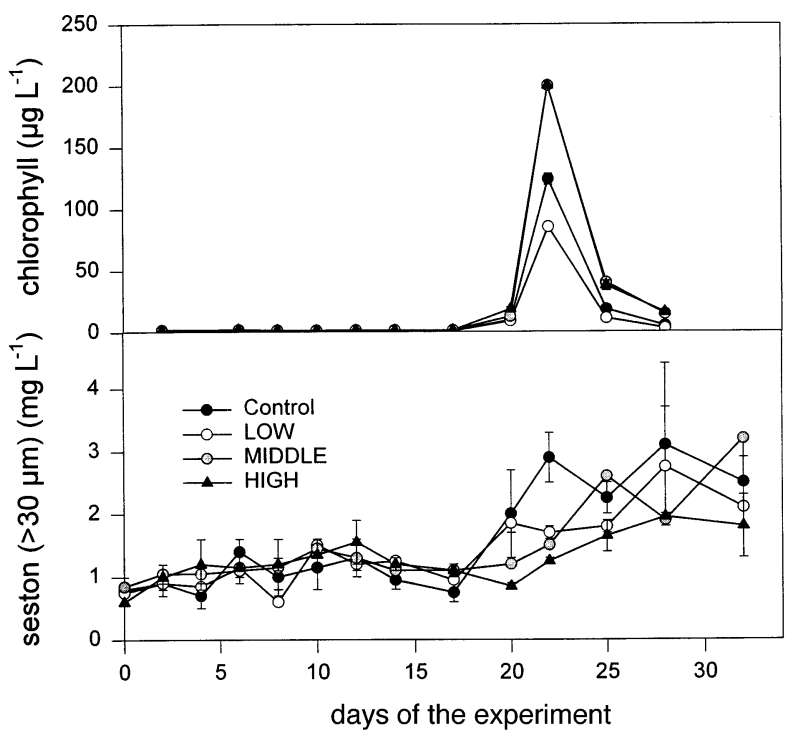

Fig. 1 Chlorophyll $a\left(\mu \mathrm{g} \mathrm{L}^{-1}\right)$, and total dry weight of the seston fraction $>30 \mu \mathrm{m}\left(\mathrm{mg} \mathrm{L}^{-1}\right)$ in the different enclosures. 


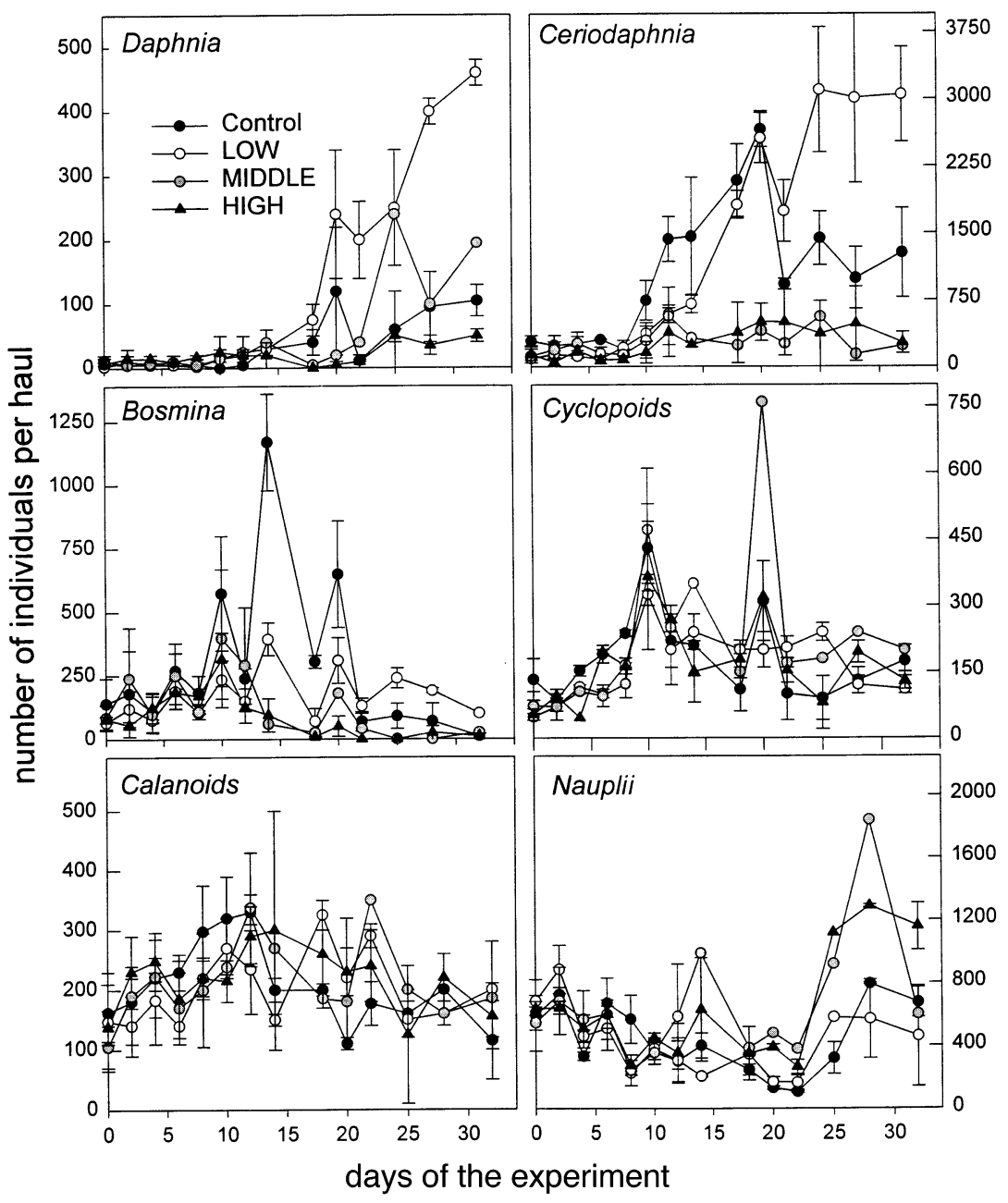

Fig. 2 Densities of crustacean zooplankton in the enclosures with different treatments. Error bars represent standard errors. One of the enclosures in the MIDDLE-treatment was lost at day 12 of the experiment.

ing the total biomass unaffected. Therefore, we counted individual animal species to investigate the effect of the additions. Counts of crustaceans revealed significant differences between treatments, but these differences were not according to expectations if highly unsaturated fatty acids actually limit growth (Fig. 2). The density of Daphnia, mainly D. hyalina $x$ galeata Floessner, was highest in the treatment with only saturated fatty acids (LOW) (Table 1). There were no significant differences between the three other treatments. Essentially the same picture emerged for Ceriodaphnia pulchella Sars: the highest density in the LOW treatments. Bosmina longirostris Müller showed the highest density in the control enclosures, whereas the cyclopoids (mainly Thermocyclops oithonoides Sars and Mesocyclops leuckarti Claus) and calanoid (Eudiaptomus gracilis Sars and E. graciloides Lilljeborg) copepods did not show any detectable responses to the different treatments. Only for the nauplii, which were counted as one group, did we observe significantly higher density in the enclosures which contained highly unsaturated fatty acids, and then only later in the experiment.

Three different rotifer taxa were common in the enclosures, Keratella cochlearis Gosse, Synchaeta pectinata Ehrenberg, and Polyarthra sp. Ehrenberg (Fig. 3). The last two species showed no significant differences in its density between the different treatments. In the first part of the experiment, an increase in numbers was observed, which was followed by a decline in all cases. This was also found for Synchaeta, but peak density varied between treatments, resulting in a sig- 
nificant treatment effect. The pattern was different for Keratella. We observed significantly higher density for the animals given the HIGH treatment. Also the control enclosures contained significantly higher amounts of Keratella than the LOW and MIDDLE treatments.

The algal community changed considerably between the two sampling dates, and was obviously completely dominated by Scenedesmus on the second sampling date. However, the differences between the treatments, as illustrated by Fig. 4 were small. The bacterial numbers were higher on the second sampling date than on the first one, with small differences between the treatments at first, and larger differences on the second sampling date (Fig. 5). On the second sampling date, we observed two-fold differences: bacterial densities in the LOW and HIGH treatments were highest.

\section{Discussion}

Enclosure and field investigations are necessarily hampered by the fact that the understanding obtained is more phenomenological than mechanistic. In other words, we observe certain changes in density, but can try to relate these only to the different treatments or to changes in other uncontrolled factors in the field. However, due to the complexity of such semi-natural systems, it is often not possible to gain a thorough understanding of the factors causing the differences observed. Enclosure studies are a step beyond field correlations, as they provide the means to manipulate conditions and are well suited to generate ideas and testable hypotheses. We set out to observe the reactions of the whole zooplankton community to the addition of emulsions of different fatty acids. It is important to note, however, that we did not aim to describe the equilibrial stages of different enclosures under different treatments, as these might show different responses (McCauley, pers. comm.). Thus, after 30 days, the density of zooplankter was still changing.

We observed differences in the zooplankton community between the different fatty acid treatments. This was caused by the different reactions of the different taxa to the treatments. Unfortunately, one of the replicates of the MIDDLE treatment was lost at day 12 of the experiment. As a result, the changes in density are rather erratic and we omit this treatment from the discussion below. Of the rotifers, only Keratella cochlearis managed to survive in some treatments, and the highest density was observed in the HIGH treatment, i.e. the treatment with the highest percentage of highly unsaturated fatty acids added. Polyarthra sp. and Synchaeta pectinata were driven to extinction in all enclosures, the process being much quicker in Synchaeta. Probably, the absence of cryptophytes in the second phase of the experiment explains these patterns, as Synchaeta and Polyarthra are highly selective feeders, mainly foraging on small motile algae (Gilbert \& Bogdan, 1984). Moreover, as a result of their selective feeding, these species probably did not take up the fatty acid emulsions. Neither did Polyarthra and Synchaeta benefit from the addition of the Scenedesmus, as they do not normally feed on green algae. It is likely that, Polyarthra and Synchaeta starved, which is also illustrated by the very low egg ratios for Polyarthra in the second part of the experiment (average egg ratio was below $0.1 \mathrm{egg}$ animal $^{-1}$ ).

Table 1 Results of repeated measure ANOVAs, with treatment as the fixed factor, and the different samples through time as the repeated measure, and the densities of the different taxa as dependent variables. $F$ and $P$-values are shown. Degrees of freedom were 3 for treatment, 13 for time, and 39 for the treatment $\times$ time interaction

\begin{tabular}{lccrcrc}
\hline & Treatment & $P$ & Time & $P$ & Treatment $\times$ time & $P$ \\
\hline Daphnia & 33.2 & 0.008 & 13.0 & $<0.001$ & 4.3 & $<0.001$ \\
Ceriodaphnia & 15.3 & 0.025 & 10.2 & $<0.001$ & 3.9 & $<0.001$ \\
Bosmina & 12.7 & 0.033 & 7.6 & $<0.001$ & 3.6 & $<0.001$ \\
Cyclopoids & 2.7 & 0.215 & 13.9 & $<0.001$ & 2.2 & 0.008 \\
Calanoids & 0.1 & 0.945 & 1.9 & 0.064 & 0.7 & 0.879 \\
Nauplia & 10.0 & 0.045 & 12.9 & $<0.001$ & 2.7 & $<0.001$ \\
Keratella & 90.4 & 0.001 & 9.7 & $<0.001$ & 2.5 & 0.002 \\
Polyarthra & 4.4 & 0.125 & 16.9 & $<0.001$ & 0.8 & 0.765 \\
Synchaeta & 27.8 & 0.011 & 199.6 & $<0.001$ & 8.0 & $<0.001$ \\
\hline
\end{tabular}




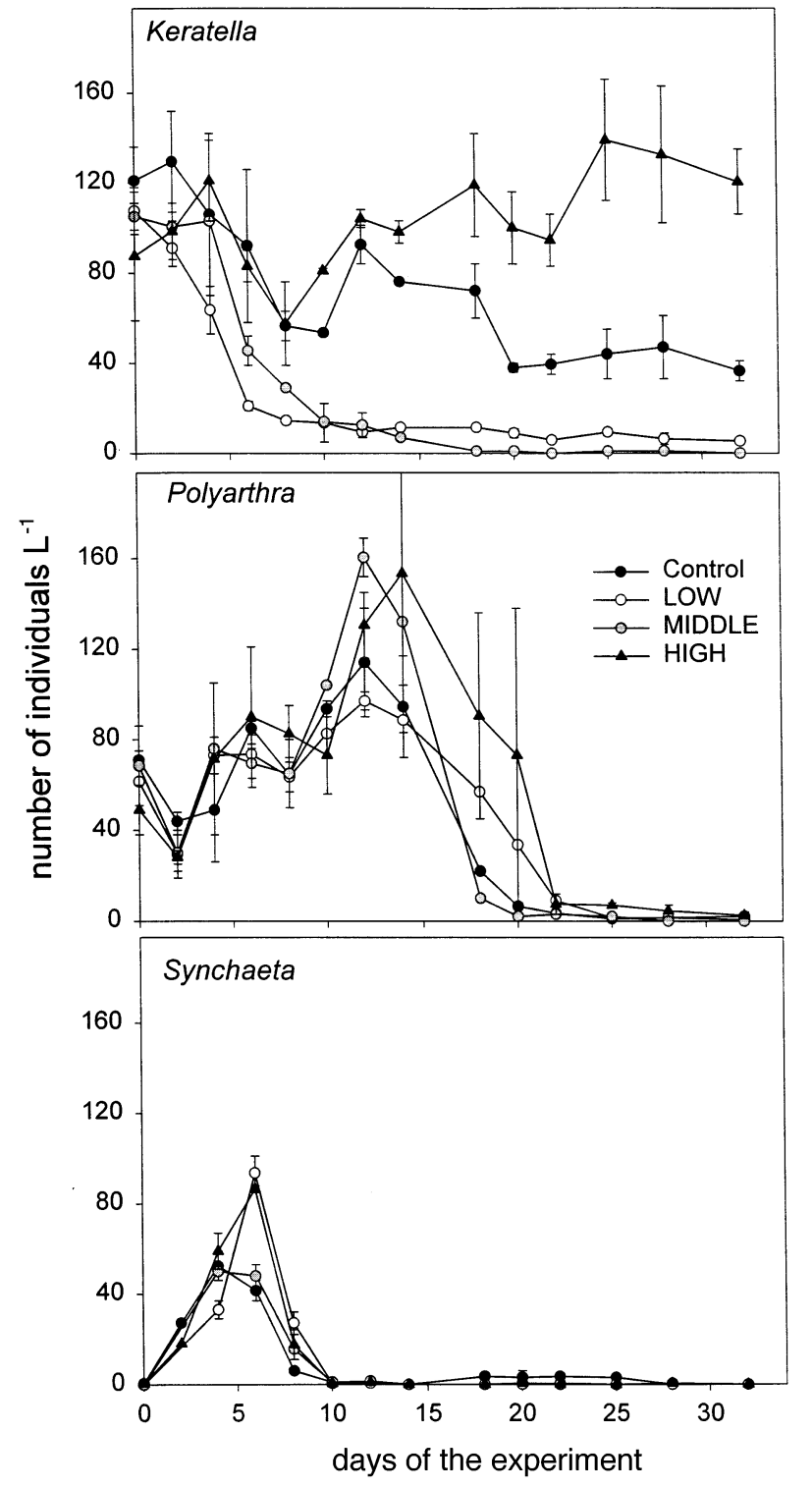

Fig. 3 Densities of different rotifers in the enclosures with different treatments. Error bars represent standard errors. One of the enclosures in the MIDDLE-treatment was lost at day 12 of the experiment.

The crustacean zooplankton density showed considerable changes during the course of the experiment. The reaction to the different treatments was not identical for the different taxa. Bosmina showed small differences between the treatments, with the highest density in the control treatments on several occasions. Bosmina species are highly selective feeders (DeMott \& Kerfoot, 1982), and probably did not take up the fatty acid emulsions. For the adult calanoid and cyclopoid copepods, we did not observe any differences in density between the different treatments. The most likely cause is that the generation time for copepods is much longer than that for cladocerans, and hence a change in density of adults and copepodites should take longer than the duration of the experiment. In fact, in the last part of the experiment we observed an increase in the density of the nauplii, which were counted as one group, and this group was most numerous in the enclosures with the highly unsaturated fatty acids added. It is tempting to speculate that the adults, taking up the highly unsaturated fatty acids through prey containing these substances, were better fed and, as a result, produced more nauplii. We did not measure the density of the nauplii of cyclopoids and calanoids separately. Therefore, we cannot test the hypothesis that there should be more cyclopoid nauplii than calanoids (because copepodites and adults of cyclopoids feed on rotifers and small cladocerans).

We observed different patterns for the non-selective cladocerans Daphnia and Ceriodaphnia. The density of both taxa changed during the experiment, and showed significant differences between treatments. Surprisingly, both taxa reached the highest density when we added the emulsions of saturated fatty acids only. This was unexpected since these fatty acids can be synthesized by consumers, although they could have been used simply as an energy source. For both taxa, the lowest density was found when we added the HIGH emulsions, whereas density in the MIDDLE emulsions was similar to that in the control for Daphnia, and for Ceriodaphnia they were significantly lower. Possibly, there were flaws in the methodology. Perhaps the constant addition of the fatty acids resulted in such high levels of these substances, since the enclosures were not flow-through systems, that they became toxic to the cladocerans. However, any toxicity seemed to be limited to the unsaturated emulsions. Moreover, other species, such as Keratella cochlearis, did grow in the enclosures with the unsaturated emulsions. Alternatively, it is possible that the different emulsions had different stability or adhesive properties to the plastic walls of the enclosures. As a result of the form in which the fatty acids were added, it was not possible to check the level of fatty acids present in the enclosures. Filtering would have resulted in the adhesion of a small part to the filter, and the loss of most of the emulsions, and for centrifugation we would have needed around $10 \mathrm{~L}$ of 


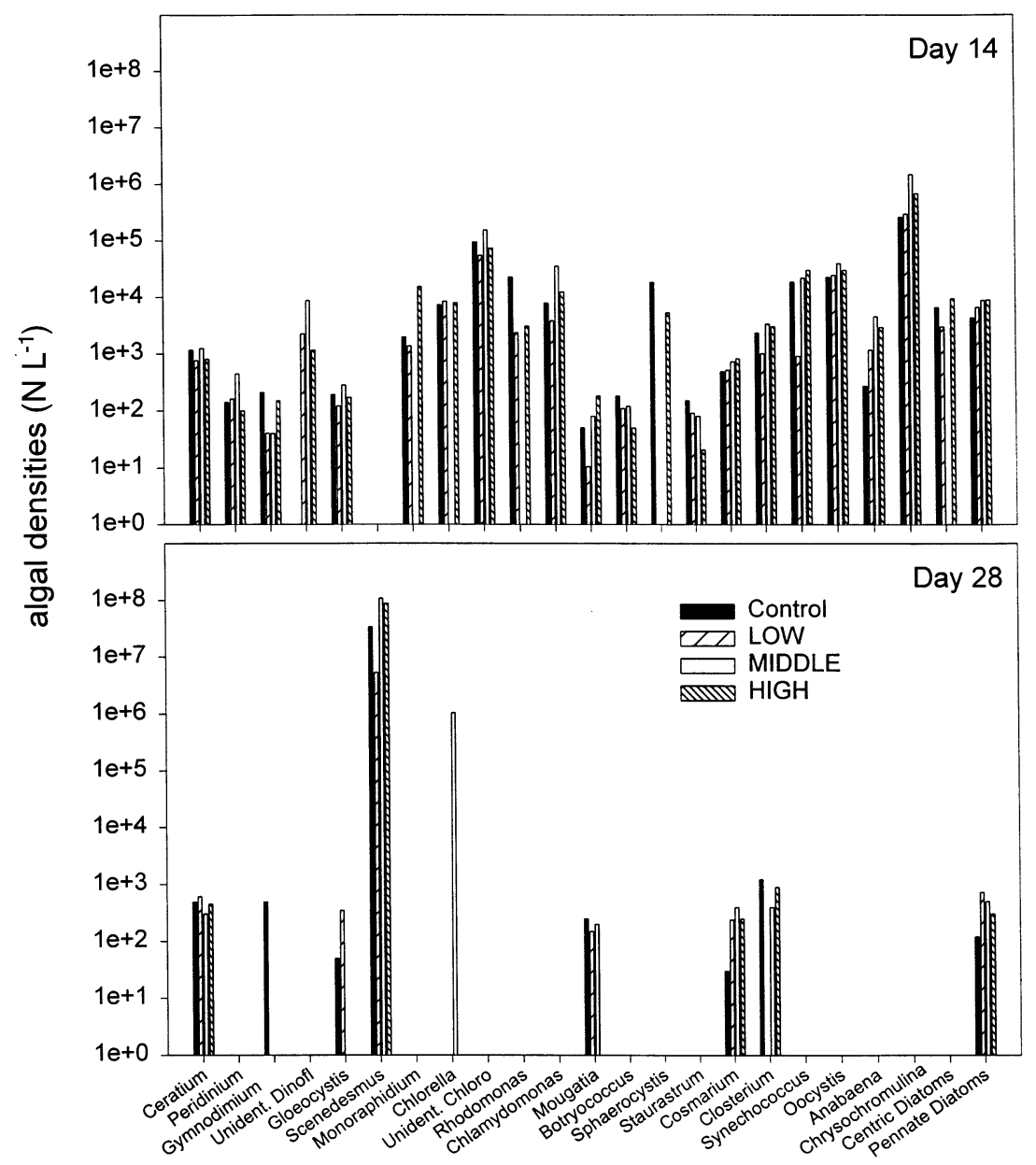

Fig. 4 Algal densities on day 14 and day 28 of the experiment.

sample to obtain enough material for the analysis of fatty acids. A final possible explanation is that, through the addition of the different emulsions, the overall food conditions for the zooplankters changed. The analysis of the algal community, however, did not reveal large differences between the treatments (Fig. 4). Moreover, although there seemed to be an overall increase in bacterial biomass in the enclosures with emulsions, the differences in bacterial density were not sufficient to explain the large differences in density of the cladocerans (Fig. 5) between the HIGH and LOW treatments. In short, these post-hoc hypotheses are either difficult to test, or unlikely. Perhaps the non-selective cladocerans were not specifically limited by highly unsaturated fatty acids but rather simply by energy. To test this hypothesis we carried out an additional laboratory experiment, described below.

(C) 2000 Blackwell Science Ltd, Freshwater Biology, 45, 179-188
Apart from the very short period of high food levels when we added the Scenedesmus, the chlorophyll concentration was low (Fig. 1). This was be-

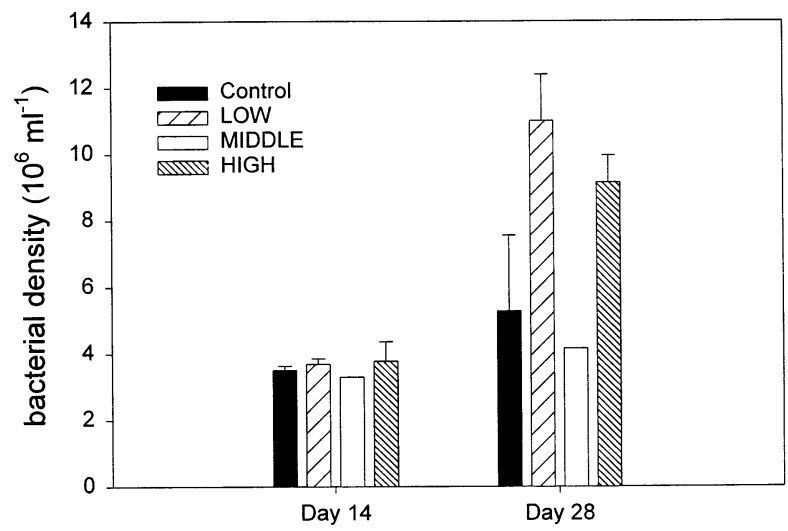

Fig. 5 Bacteria densities on day 14 and day 28 of the experiment. Error bars represent standard errors. 


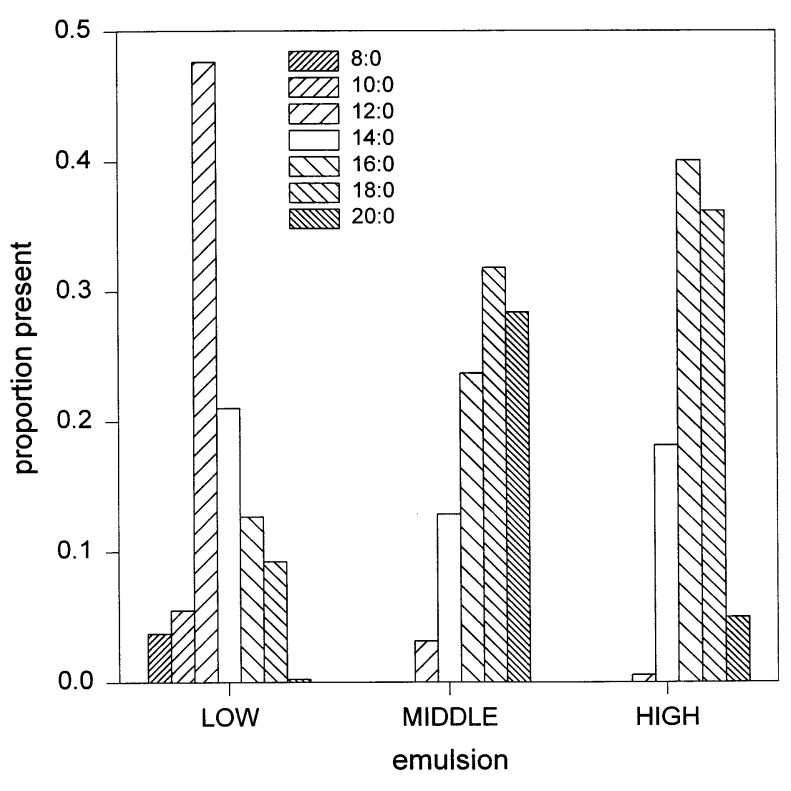

Fig. 6 Relative composition of the saturated part of the different emulsions, ranging from caprylatic acid (8:0) to arachidic acid (20:0). The average chain length of the saturated fatty acids ranges from 13.5 for the LOW-emulsion to 16.5-17.4 for the MIDDLE and HIGH emulsions.

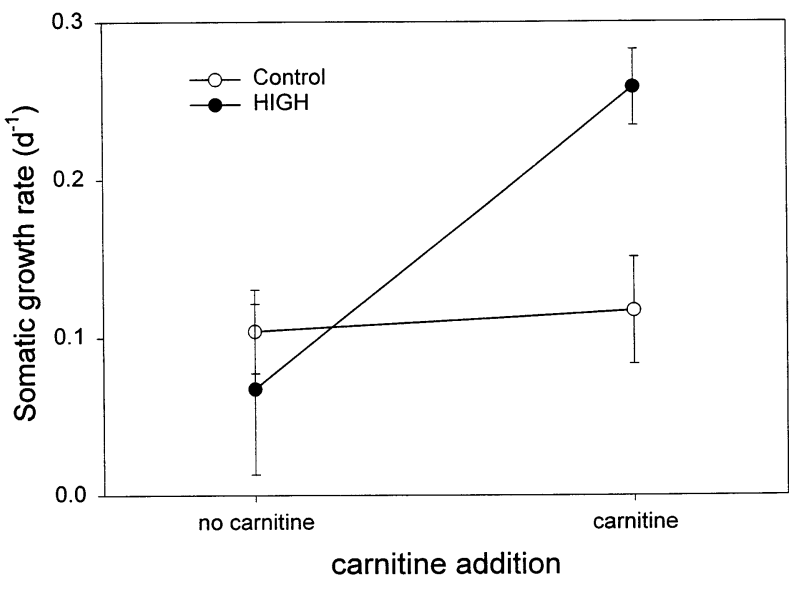

Fig. 7 Somatic growth of newborn daphnids, grown at $20^{\circ} \mathrm{C}$, with an algal food content of $0.1 \mathrm{mg} \mathrm{C} \mathrm{L}^{-1}$, and HIGH emulsions and carnitine added.

cause the experiment was carried out around the clear-water phase in Schöhsee, with very low levels of food. An explanation of the high growth on the fully saturated fatty acid emulsions is possibly the difference in composition of these emulsions. Obviously, there was a difference in the content of unsaturated fatty acids, but also the saturated fatty acids showed differences between the emulsions. Fig. 6 shows the content of these saturated fatty acids relative to the total amount of saturated fatty acids. What becomes clear is that the average length of the saturated fatty acids in the LOW emulsions was much shorter than the length of the saturated fatty acids in the MIDDLE and HIGH treatments. This might be of importance, as in beta-oxidation shorter fatty acids are transported through the membranes after activation with -CoA only, whereas the longer ones need a special transport mechanism. Activated long-chain fatty acids are carried across the inner mitochondrial membrane by carnitine, a zwitterionic compound formed by lysine (Stryer, 1988). A shortage of carnitine could lead to a reduced metabolism of longer chained fatty acids. As carnitine is a compound formed from lysine, an essential amino acid for humans, this implies that a shortage of lysine could cause a reduction in the metabolism of longer chained fatty acids. To test this hypothesis, we carried out a life-history experiment in the laboratory with a Daphnia galeata $x$ hyalina clone. Newborn daphnids were fed a low concentration of Scenedesmus obliquus (algal carbon content of $0.1 \mathrm{mg} \mathrm{C} \mathrm{L}^{-1}$ ) to make sure that the animals were food limited, and somatic growth rates in the first 3 days of the daphnids' life were established. The experiment was carried out at $20^{\circ} \mathrm{C}$, at a day night cycle of $16: 8 \mathrm{~h}$. We had four treatments, with and without the $\mathrm{HIGH}$-emulsion $\left(0.1 \mathrm{mg} \mathrm{C} \mathrm{L}^{-1}\right)$, and with and without the addition of carnitine $\left(0.1 \mathrm{mg} \mathrm{L}^{-1}\right)$ in a factorial design. We observed a significant effect of the carnitine addition, (two way ANOVA, emulsion addition and carnitine addition as fixed factors) $F_{1,35}=8.27 ; P=0.007$. The effect of the addition of the emulsions was not significant $\left(F_{1,35}=\right.$ 2.17; $P=0.149)$, but the interaction was $\left(F_{1,35}=6.26\right.$; $P=0.017)$, showing an increase in growth when given HIGH emulsions as a result of the carnitine addition. Due to the low algal food level, the daphnids were probably energy (carbon) and not HUFA limited (see also Sterner \& Robinson, 1994), and hence the growth rate increased as a result of the carnitine addition (Fig. 7). Currently, the importance of essential amino acids (Lie et al., 1997), and derivates such as carnitine (Froyland et al., 1998) attracts a substantial amount of research in aquatic systems and aquaculture, and this interaction between essential amino acids and fatty acids certainly warrants further investigation. If the difference in length of the saturated fatty acids in the emulsions is the explanation for our observations, this means that 
we must conclude that during our enclosure experiment the cladocerans were not HUFA-limited but energy-limited. Easier transport through the membranes, and oxidization of the shorter fatty acids, led to an increase in growth.

In summary, from our experiments we must conclude that we cannot simply state that HUFAs are important or not. In our experiment the effect of the HUFA additions was probably dependent on the selectivity of the different organisms, and also on the very poor food availability of natural food at the same time. As a result, we did not find a significant increase in density for the non-selective cladocerans; only Keratella cochlearis seemed to be really HUFAlimited in our experiments, and the non-selective cladocerans seemed to be energy limited. This implies that zooplankters, with similar feeding modes, can be limited by different factors in their food, which could indeed explain why so many different organisms are found in the plankton (Hutchinson, 1961). We conclude that different factors are probably important at different times of the year, and expect that there are few if any lakes, in which any one factor dominates zooplankton dynamics.

\section{Acknowledgments}

We thank Heinke Buhtz and Anita Möller for their assistance during the experiment. We also thank Thomas Hansen for the chemical analyses, Sabine Flöder for the algal counts, and Karen Wiltshire for her constant interest in our work. We are grateful to Karl-Otto Rothhaupt for the organisation of such an exciting symposium, and thank Ed McCauley, Sebastian Diehl and Jef Huisman for the stimulating discussions.

\section{References}

Bern L. (1994) Particle selection over a broad size range by crustacean zooplankton. Freshwater Biology, 32, 105-112.

Boersma M. The nutritional quality of P-limited algae for Daphnia. Limnology and Oceanography (in press).

Boersma M. \& Vijverberg J. (1995) Synergistic effects of different food species on life-history traits of Daphnia galeata. Hydrobiologia, 307, 109-115.
Brendelberger H. (1991) Filter mesh size of cladocerans predicts retention efficiency for bacteria. Limnology and Oceanography, 36, 884-894.

Brett M.T. \& Müller-Navarra D.C. (1997) The role of highly unsaturated fatty acids in aquatic food web processes. Freshwater Biology, 38, 483-499.

Coutteau P., Castell J.D., Ackman R.G. \& Sorgeloos P. (1996) The use of lipid emulsions as carriers for essential fatty acids in bivalves - a test case with juvenile Placopecten magellanicus. Journal of Shellfish Research, 15, 259-264.

Coutteau P. \& Sorgeloos P. (1997) Manipulation of dietary lipids, fatty acids and vitamins in zooplankton cultures. Freshwater Biology, 38, 501-512.

DeMott W.R., Gulati R.D. \& Siewertsen K. (1998) Effects of phosphorus-deficient diets on the carbon and phosphorus balance of Daphnia magna. Limnology and Oceanography, 43, 1147-1161.

DeMott W.R. \& Kerfoot W.C. (1982) Competition among cladocerans: Nature of the interaction between Bosmina and Daphnia. Ecology, 63, 1949-1966.

DeMott W.R. \& Müller-Navarra D.C. (1997) The importance of highly unsaturated fatty acids in zooplankton nutrition: evidence from experiments with Daphnia, a cyanobacterium and lipid emulsions. Freshwater Biology, 38, 649-664.

Elser J.J. \& Hassett R.P. (1994) A stoichiometric analysis of the zooplankton-phytoplankton interaction in marine and freshwater ecosystems. Nature, 370, 211-213.

Froyland L., Madsen L., Eckhoff K.M., Lie O. \& Berge R.K. (1998) Carnitine palmitoyltransferase i, carnitine palmitoyltransferase ii, and acyl-coa oxidase activities in atlantic salmon (Salmo salar). Lipids, 33, 923-930.

Gilbert J.J. \& Bogdan K.G. (1984) Rotifer grazing: in situ studies on selectivity and rates. In: Trophic Interactions Within Aquatic Ecosystems. American Association for the Advancement of Science, Selected Symposium 85, Boulder, Colorado, USA (eds D.G. Meyers \& J.R. Strickler), pp. 97-133.

Goulden C.E., Moeller R.E., McNair J.N. \& Place A.R. (1998) Lipid dietary dependencies in zooplankton. In: Lipids in Freshwater Ecosystems (eds M.T. Arts \& B.C. Wainman). Springer, New York.

Gulati R.D. \& DeMott W.R. (1997) The Role of Food Quality for Zooplankton. Blackwell, Oxford.

Hessen D.O. (1992) Nutrient element limitation of zooplankton production. American Naturalist, 140, 799-814. 
Hutchinson G.E. (1961) The paradox of the plankton. American Naturalist, 95, 137-145.

Lie O., Haaland H., Hemre G.I., Maage A., Lied E., Rosenlund G., Sandnes K. \& Olsen Y. (1997) Nutritional composition of rotifers following a change in diet from yeast and emulsified oil to microalgae. Aquaculture International, 5, 427-438.

Lundstedt L. \& Brett M.T. (1991) Differential growth rates of 3 cladoceran species in response to monoalgal and mixed-algal cultures. Limnology and Oceanography, 36, 159-165.

Müller-Navarra D. (1995a) Evidence that a highly unsaturated fatty acid limits Daphnia growth in nature. Archiv für Hydrobiologie, 132, 297-307.

Müller-Navarra D.C. (1995b) Biochemical versus mineral limitation in Daphnia. Limnology and Oceanography, 40, 1209-1214.

Porter K.G. (1976) Enhancement of algal growth and productivity by grazing zooplankton. Science, 192, 1332-1334.

Porter K.G. \& Feig Y.S. (1980) The use of DAPI for identification and counting aquatic microflora. Limnology and Oceanography, 25, 943-948.

Sterner R.W. (1993) Daphnia growth on varying quality of Scenedesmus: mineral limitation of zooplankton. Ecology, 74, 2351-2360.

Sterner R.W., Hagemeier D.D. \& Smith W.L. (1993) Phytoplankton nutrient limitation and food quality for Daphnia. Limnology and Oceanography, 38, 857871.

Sterner R.W., Elser J.J., Fee E.J., Guildford S.J. \& Chrzanowski T.H. (1997) The light: nutrient ratio in lakes: the balance of energy and materials affects ecosystem structure and process. American Naturalist, 150, 663-684.

Sterner R.W. \& Robinson J.L. (1994) Thresholds for growth in Daphnia magna with high and low phosphorus diets. Limnology and Oceanography, 39, 12281232.

Sterner R.W. \& Schulz K.L. (1998) Zooplankton nutrition: recent progress and a reality check. Aquatic Ecology, 32, 261-279.

Stryer L. (1988) Biochemistry. Freeman and Company, New York.

Sundbom M. \& Vrede T. (1997) Effects of fatty acid and phosphorus content of food on the growth, survival and reproduction of Daphnia. Freshwater Biology, 38, 665-674.

Urabe J., Clasen J. \& Sterner R.W. (1997) Phosphorus limitation of Daphnia growth: is it real? Limnology and Oceanography, 42, 1436-1443.

van Donk E., Lürling M., Hessen D.O. \& Lokhorst G.M. (1997) Altered cell wall morphology in nutrient-deficient phytoplankton and its impact on grazers. Limnology and Oceanography, 42, 357-364.

Weers P.M.M. \& Gulati R.D. (1997a) Effect of the addition of polyunsaturated fatty acids to the diet on the growth and fecundity of Daphnia galeata. Freshwater Biology, 38, 721-729.

Weers P.M.M. \& Gulati R.D. (1997b) Growth and reproduction of Daphnia galeata in response to changes in fatty acids, phosphorus, and nitrogen in Chlamydomonas reinhardtii. Limnology and Oceanography, 42, 1584-1589.

(Manuscript accepted 5 June 2000) 